\title{
Does Trust Influence the Informal Lending Decision? An Investigative Analysis
}

\author{
Ntiedo John Umoren
}

Department of Business Management, University of Uyo

\section{ABSTRACT}

This study analysed the role of trust in informal lending decision-making process. By applying verbal protocol analysis, this paper empirically examined the role of trust and cooperation in lender's initial reaction to potential lending opportunities, and the lender's assessment of the intermediary responsible for providing the initial referral of the lending opportunity. The results corroborate earlier findings, and provide sufficient evidence to confirm that about 93 per cent of lending opportunities presented to informal lenders are rejected. It also shows that considerable reliance is placed on the brokers presenting the opportunities. The result also indicates that the dearth of entrepreneurial development in Nigeria is tied implicitly to the instant trust and instant cooperation paradigm.

JEL G29, M00

\section{INTRODUCTION}

Informal lending institutions and settings constitute a major component of most economies, especially in Sub-Saharan Africa where markets for informal financial products are enormous. As would be expected, informal lending sources seek sound and safe investment opportunities hence they derive their primary clientele from new and developing entrepreneurial ventures. Like the informal venture capital market, research in this area focuses on the characteristics of the markets and their policy implications, but without any appropriate theoretical frameworks. The few isolated studies tend to concentrate on the outcomes of the lending/investment process and ignore the issues surrounding the process of such informal lending.

In order to address these two issues, this paper attempts to develop a framework for the clarification of the concepts of instant trust and instant cooperation. This will facilitate the development of an operational framework for analysing trust and cooperation, which can be applied to informal lending-decision making. The 
study applies verbal protocol analysis on the lender's reactions in real time on two particular investment opportunities. This approach facilitates the empirical examination of the role of trust and cooperation in lender's nitial screening of potential lending opportunities, and the lender's assessment of the intermediary responsible for providing the initial referral of the lending opportunity.

In Nigeria, and indeed Africa, as in the United States and parts of Europe, a good number of studies have focused on the role of informal lending and investment directed at entrepreneurial activities (see Ekpo, 1987; Freear, Sohl, \& Wetzel, 1996; Mason \& Harrison, 1996a). These studies continue to provide empirical evidence to support the presence of informal lending activities, and due to its prescriptive emphasis, exert strong influence on public policy. Studies from some of the contributors to the subject matter such as Mason (1996), and Umoren (1998) dwell more on the understanding of how the informal lending/investment markets operate, and by so doing identify the methods by which the markets could be made to work more efficiently.

As Harrison, Dibben \& Mason observed, "research on informal venture capital has not been characterized to date by a high level of theoretical sophistication" (1997: 64). This paper will therefore attempt to explore the relevance of the concept of trust to the analysis of the informal lending market. In spite of the adoption of trust as a major element of economic relations particularly within the entrepreneurial context (see Fiet, 1991; Larson, 1992; Fukuyama, 1995), the role of trust at the preliminary stages of the lending/investing process has not been adequately explored. For purposes of clarity and the avoidance of ambiguity, trust in this context is "construed as a means of speeding decision making and negotiations by reducing transaction costs between individuals in organizations under conditions of risk" (Harrison et al., 1997: 64). Hence, the key focus of this paper is the analysis of the role of trust at earlier stages of the informal lending process.

In the sections that follow, a theoretical concept of instant trust and instant cooperation and their relevance in the informal lending/investing process is discussed. The third segment develops a model of the informal lending decisionmaking process based on the Harrison et al., model of the informal investment decision-making process, and applies this model in search of evidence of trust relationships. The last section contains the implications on entrepreneurial development in Nigeria, conclusion, and references. 


\section{TYPICAL INFORMAL LENDING DECISION SITUATION}

Following an elaborate analysis of the investment decision process by Tyebjee \& Bruno (1984) as extended by Hall \& Hofer (1993), and Mason \& Rogers (1996), it is inferred that there are five basic stages of the lending process. They include screening, evaluation, negotiation, monitoring and recovery. A sixth distinct element that is also associated, albeit independently, with this process is the intermediary factor. These six situational domains therefore provide the basis for our understanding of the role and influence of trust relations in the informal lending decision-making process.

As indicated by Fukuyama, trust is "the expectation that arises, within a community, of regular honest and cooperative behavior, based on commonly shared norms, on the part of other members of that community" (1995: 26). This definition corroborates the underlying assumption that "trust is something that emerges over time" (Harrison et al., 1997: 65). Thus, this definition can only be applied directly to our sixth situational domain where prior knowledge exists, and where the endorsement of others may be obtained. But it is not immediately relevant to the other five domains where "trust" as defined has not yet been established.

In order to include the other five domains within a trust setting, this paper focuses on how trust that is associated with lending decision-making is established within a relatively short period of time. For instance, the length of time required to institute trust is very short in the initial screening domain. And in the absence of a trust relationship, the lending decision may be negatively skewed. It is within this context that this study applies the concept of "instant trust" as a basis for cooperation between lender and borrower. This premise permits the exploration of the relevance of the concept of trust to the explication of informal lending decision making as well the processes that lead up to the development of trust relations in the first instance. Earlier exploratory analyses within the entrepreneurial context for instance (see Low \& Srivatsan, 1993) have shown that trust is essential for cooperation.

\section{INSTANT TRUST}

According to Harrison et al. (1997) 'instant trust' as conceptualized by Meyerson et al. (1996) was meant to address the emanation of trust relations in situations where the individuals have a limited knowledge or history of each other. In other words, instant trust emerges in temporary situations, and in most cases in temporary group settings. Under such circumstances, each member of the group ex ante of prior knowledge or experience confers instant trust. By 
direct analogy, informal lenders often comply with the characteristics of such temporary systems, and confer instant trust based on faith in the recipient's own ability to honour his/her obligations.

Since temporary groups have limited time to develop in order for a stronger form of trust to emerge, the instant trust is only expected to be resilient enough to survive the life of the group. However, where there is a central figure, the like of a coordinator with a strong and trustworthy reputation, the instant trust would retain a longer life span primarily due to the integrity of that central figure. In effect, the conferring of instant trust ex ante by individual members within the group is essentially influenced by the level of risk associated with the trust, the expected outcome of the association, and the coordinator's perceived ability to make the right choices.

Even though it is important to understand what originates, sustains and destroys trust, this paper contends that the most important element of trust in interpersonal relations is how trust develops and how it influences relationships (see also Gambetta, 1990, Lewicki \& Bunker, 1996). This assertion is founded on the premise that trust resides within the individual, and that it manifests in phases. Thus, trust is perceived as a recurring process that assumes a different character at three different stages of a relationship. It is against this background that Lewicki \& Bunker (1996) opined that there are three categories of situational trust, namely, Calculus-Based-Trust, Knowledge-Based-Trust, and Identification-Based Trust.

Calculus-Based-Trust is "an on-going, market-oriented, economic calculation whose value is derived by determining the outcomes resulting from creating and sustaining the relationship, relative to the costs of maintaining or severing it" (Lewicki \& Bunker, 1996: 120). In other words, it is the trust that evolves during the "sizing-up" process between individuals during the early stage of their relationship. They also define Knowledge-Based-Trust as that trust that "exists between two individuals who know each other well enough for the parties to have a history of interaction that allows each to make predictions about the other" (Harrison et al., 1997: 66). This type of trust is founded on the parties' ability to identify their common traits and similarities. The third category of situational trust is the Identification-Based-Trust, which is described as the trust that develops "because the parties effectively understand and appreciate the other's wants to such an extent that each can effectively act for the other.., and substitute for the other in interpersonal interactions" (Lewicki \& Bunker, 1996: 157). 
Whereas the Knowledge-Based-Trust and the Identification-Based-Trust deal with trust that evolves and develops over time, Calculus-Based-Trust remains the most desirable in time-compressed circumstances. Beyond the identification of these three categories of situational trust however, there exists the need to determine the key factors that may foster trusting cooperation. Harrison et al. (1997) submit that there are four factors that may influence a categorical prediction of trusting cooperation. The four determinants include perceived risk, importance, utility of the situation for the trusting individual, and the trusting individuals' perceived competence of the trusted individual. By drawing on Marsh's (1995) computation trust formalism, and our established trust criteria and the cooperation criteria as stated above, this paper developes a model for the analysis of trust in the informal lending field, and suggests how trust concepts have been handled in the empirical analysis that is given below.

\section{TRUST AND COOPERATION PROTOCOL}

Following the above discussion, this paper condenses the protocol that forms the basis for analysing trust in informal lending situations and how the concept of trust has been applied in our empirical analysis. It lays out all the fundamental elements that are necessary for the understanding of trust relations. In particular, it encompasses the trust criteria here represented by Calculus-Based-Trust, Knowledge-Based-Trust, and Identification-Based-Trust, as well as the cooperation criteria, namely, utility, importance, risk, and competence. Due to the similarity in context and character of lending and investment, this study adopts the Harrison et al. (1997) postulations on the four factors that influence the informal investment decision-making process, and transposes them to the lending decision-making process.

The four propositions are that:

1 The greater the perception of utility, the greater the possibility of trusting, cooperative behavior (where utility is associated with futuristic economic benefit).

2 The greater the perception of importance, the greater the possibility of trusting, cooperative behavior (where importance is associated with the potential of non-economic value of a situation).

3 The greater the perception of risk, the lesser the possibility of trustingcooperative behavior (where risk is associated with the potential for economic or social loss).

4 The greater the perception of competence, the greater the possibility of trusting, cooperative behavior (where competence is associated with the professional ability of the individual desiring trust). 
The initial listings of venture capitalists and business angels were obtained from the Venture Capital Report and Bureau of Cooperative listings. From these sources, it was possible to assemble a data set with sufficient informational content on private funding arrangements in Nigeria and the United States of America. Since the study focused on the initial screening of borrowers' application by lenders for possible consideration, the data used for the study were collected from primary sources in Nigeria and the United States of America. The application of the verbal protocol analysis methodology enabled us to capture the informal lenders' decision-making in real time. Based on the theory that a vocalized thought takes the form of inner speech, the verbal protocol analysis methodology requires respondents to voice out their thought while performing a particular task. The choice of this methodology instead of the more conventional interview technique was informed by the desire of the investigators to test the efficacy of this rather new technique. It was assumed that the results would be as reliable and valid as those obtainable through the other methods.

Respondents were presented with an abridged version of a loan proposal that was presented to a merchant bank by APICO Limited, a government owned property and Investment Company. In this proposal, APICO sought for a medium term loan of 1.bn to finance the development of housing units in Uyo, the Akwa Ibom State capital. The company has land concessions in excess of 20 hectares across Akwa Ibom State, and the loan application is fully backed by the State government guarantee. Akwa Ibom State is experiencing a boom in industrial growth, a situation that has triggered a huge demand for residential accommodation in the State. APICO marks up the value of each completed home by 33 per cent and completes the sale for cash within 30 days. Each housing unit is completed within a 90-day construction-to-sale cycle. The chief executive officer of APICO is a seasoned architect with a strong background in management.

A total of 30 respondents drawn from informal financing outlets in Nigeria were asked to review this loan proposal, which falls within the ambit of their regular business opportunity profile. They were required to verbalize their thoughts as they read this loan proposal. In other words, they were asked to say out loud, whatever thoughts came to their mind as they read the proposal. The verbalized thoughts were manually recorded and coded according to statement type protocol (Table 1).

Another group of respondents was presented with a similar loan-based investment opportunity. In this proposal the company sought a short-term loan of $\$ 45,000$ (forty-five thousand US dollars) to strengthen its liquidity position following a cash buyout of a competitor. With this purchase, the company's 
market share rose from 16 per cent to 22 per cent, and a growth potential of 2.7 per cent annually. As collateral, the company offered its combined inventory of seasonal goods currently valued at \$172,000 (one hundred and seventy-two thousand US dollars). A statement type protocol was also employed for this group.

A total of 30 informal venture capitalists and business angels located in and around the Washington metropolitan area in the United States of America were asked to review this loan proposal. Another group of 30 respondents from Nigeria and the United States were also asked to review a mixture of the two opportunities through two reputable brokerage firms. The same verbal protocol analysis was applied in all cases in order to explore the role of trust in informal lenders' decision-making at the application screening stage. This approach would also enable the researcher to examine how instant trust may be influenced by the involvement of the brokerage firms.

The result is presented in two segments. The first segment deals with the outcome of the verbal protocol analysis as applied to the first situational domain - the screening stage of the loan application. The second presents evidence of the influence of an intermediary on instant trust and instant cooperation.

\section{EVIDENCE OF TRUST AND COOPERATION}

Eighty-five (or 95 per cent) of the respondents rejected the proposal as an investment opportunity, while five (or 5 per cent) sought clarification from the potential borrower that would enable them to consider further examination of the loan proposals. This result is consistent with similar studies on investment behaviors of business angels that have since established that "between 93 per cent and 97 per cent of investment proposals received by business angels are rejected" (Harrison et al., 1997: 70). On average, each potential lender spent between five and 35 minutes reviewing the proposals.

As the summary of the 582 coded thought units later reveals, lenders that spent the least time on the proposals appear to have preconceived rejection. The matrix of the evaluation criteria and statement type reveals that the dominant situational trust is the Calculus-Based-Trust while the dominant thought units are preconception and inference. At the lower rung of the thought units are question, comment, recall, action and description (in that order) that account for the least thought units advanced by the informal lenders in our study.

From this result, the traditional notion of fragility of Calculus-Based-Trust tends to be confirmed. This situational domain seems to explain why most of the 
lenders in our study tended to look for reasons to reject the loan proposals that were presented to them for consideration. By design, this study did not advance to the next two situational domains, namely, Knowledge-Based Trust and Identification-Based Trust in order to verify informal lenders' decision at these levels.

At the level of instant cooperation, the analysis revealed that the dominant thoughts were on the competence of the entrepreneur (37 per cent). This is consistent with the perceived view of the importance of the management team in informal investment decision. The ranking of the remainder of the cooperation thought units are risk thoughts that account for 21 per cent, coordinator judgment accounts for 20 per cent, utility ranks accounts for 13 per cent, while importance ranks the lowest at 5 per cent.

The results in tables 3,4 and 5 indicate a very strong positive correlation particularly at the thought unit levels where preconception is dominant. The bias becomes slightly more visible when the result from Nigeria is placed side-byside with the respondents from the United States of America.

\section{Table 1 Thought segment protocol}

\begin{tabular}{||l|l||}
\hline & \multicolumn{1}{c||}{ Statement type } \\
\hline Description & $\begin{array}{l}\text { Non-evaluative statement consisting of verbatim or paraphrased } \\
\text { quotation of information presented in the plan }\end{array}$ \\
\hline Recall & $\begin{array}{l}\text { Non-evaluative information based on the past experience of the } \\
\text { respondent }\end{array}$ \\
\hline Preconception & $\begin{array}{l}\text { Judgmental statement based on previous experience/background } \\
\text { knowledge }\end{array}$ \\
\hline Inference & Statement that involves a judgment on some part of the plan \\
\hline Question & Statement that seeks further information \\
\hline Action & $\begin{array}{l}\text { Statement of intention or action to be performed (e.g., to search } \\
\text { for source of information) }\end{array}$ \\
\hline Comment & Irrelevant statement that cannot be coded \\
\hline
\end{tabular}

Source: Harrison et al., 1997 


\section{Table 2 Evaluation criteria}

\begin{tabular}{||l|l|l||}
\hline \hline A & \multicolumn{1}{|c|}{$\begin{array}{c}\text { Instant trust } \\
\text { criteria }\end{array}$} & \multicolumn{1}{c||}{ Description } \\
\hline 1 & $\begin{array}{l}\text { Calculus-Based } \\
\text { Trust }\end{array}$ & $\begin{array}{l}\text { Trust that is formed between individuals on the basis } \\
\text { of what each sees he/she can get out of the relationship } \\
\text { characterized by intimation of difference between } \\
\text { individuals, and a lack of shared knowledge of the } \\
\text { product/market situation. } \\
\text { Trust that is formed between individuals with shared } \\
\text { knowledge of the product/market situation. } \\
\text { Characterized by intimations of the agreement } \\
\text { between individuals, leading to perceptions of } \\
\text { predictability and thus reductions of uncertainty. }\end{array}$ \\
\hline 3 & $\begin{array}{l}\text { Knowledge- } \\
\text { Based Trust } \\
\text { Irust that is formed between individuals with a high } \\
\text { Begree of identification with the wishes/intentions of } \\
\text { the other party. Characterized by strong agreement } \\
\text { between the individuals, and intimations of the mutual } \\
\text { sharing of values. }\end{array}$ \\
\hline \hline
\end{tabular}

\begin{tabular}{|l|l|l||}
\hline B & $\begin{array}{l}\text { Instant coope- } \\
\text { ration criteria }\end{array}$ & \multicolumn{1}{|c||}{ Description } \\
\hline a & Utility & $\begin{array}{l}\text { An individual's perception of the potential economic } \\
\text { value of a situation. }\end{array}$ \\
\hline b & Importance & $\begin{array}{l}\text { An individual's perception of the potential of non- } \\
\text { economic value of a situation. }\end{array}$ \\
\hline c & Risk & $\begin{array}{l}\text { An individual's perception of the potential loss from a } \\
\text { situation. }\end{array}$ \\
\hline d & Competence & $\begin{array}{l}\text { An individual's perception of the professional ability } \\
\text { of another individual. Characterized by comments } \\
\text { regarding (e.g.) market analysis, data availability, } \\
\text { quality, etc. }\end{array}$ \\
\hline e & $\begin{array}{l}\text { Coordinator } \\
\text { Judgment }\end{array}$ & $\begin{array}{l}\text { An individual's perception of the coordinating party's } \\
\text { ability to select potentially successful opportunities for } \\
\text { investment. }\end{array}$ \\
\hline f & Other & $\begin{array}{l}\text { Comments on any other aspects of the business that } \\
\text { cannot be coded in any other category. }\end{array}$ \\
\hline
\end{tabular}

Harrison et al., 1997 
Table 3 Verbal protocol frequency analysis for 30 Nigerian lenders

Legend: (refer to Table 1)

$\mathrm{A}=$ Description

$\mathrm{B}=$ Recall

$\mathrm{C}=$ Preconception

$\mathrm{D}=$ Inference

$\mathrm{E}=$ Question

$\mathrm{F}=$ Action

$\mathrm{G}=$ Comment

$\mathrm{H}=$ Total number

$\mathrm{I}=$ Total percentage
Legend: (refer to Table 2)

$\mathrm{CBT}=$ Calculus-Based Trust

$\mathrm{KBT}=$ Knowledge-Based Trust

IBT $=$ Identification-Based Trust

$\mathrm{U}=$ Utility

$\mathrm{I}=$ Importance

$\mathrm{R}=$ Risk

$\mathrm{C}=$ Competence

$\mathrm{CJ}=$ Coordinator Judgment

$\mathrm{O}=$ Others

\begin{tabular}{||cccccccccc||}
\hline CBT & A & B & C & D & E & F & G & H & I \\
KBT & - & - & 17 & 23 & - & - & 1 & 41 & $\mathbf{1 7 . 4}$ \\
IBT & - & 1 & 2 & 2 & & & - & 5 & $\mathbf{2 . 1}$ \\
U Low & - & - & 3 & 5 & - & 1 & 1 & 10 & $\mathbf{4 . 2}$ \\
U Med & - & 3 & 3 & 2 & - & - & - & 8 & $\mathbf{3 . 4}$ \\
U High & - & - & 2 & 1 & - & - & - & 3 & $\mathbf{1 . 3}$ \\
I Low & - & 3 & - & 3 & - & - & 2 & 8 & $\mathbf{3 . 4}$ \\
I Med & - & - & 1 & - & 1 & - & - & 2 & $\mathbf{0 . 8}$ \\
I High & - & 1 & - & - & - & 1 & 2 & 4 & $\mathbf{1 . 7}$ \\
R Low & - & - & 1 & 3 & 1 & - & - & 5 & $\mathbf{2 . 1}$ \\
R Med & - & - & 11 & 1 & 1 & - & - & 13 & $\mathbf{5 . 5}$ \\
R High & 1 & 2 & 15 & 2 & 1 & - & 1 & 22 & $\mathbf{9 . 3}$ \\
C Low & - & 1 & 8 & 28 & 14 & 4 & 6 & 61 & $\mathbf{2 5 . 8}$ \\
C Med & - & - & - & 5 & - & 1 & - & 6 & $\mathbf{2 . 5}$ \\
C High & - & - & - & - & - & - & - & - & \\
CJ Low & 1 & 1 & 9 & 2 & 3 & - & 5 & 21 & $\mathbf{8 . 9}$ \\
CJ Med & - & 1 & 1 & 2 & - & - & - & 4 & $\mathbf{1 . 7}$ \\
CJ High & - & - & 3 & 1 & - & - & 2 & 6 & $\mathbf{2 . 5}$ \\
Other & - & - & 6 & 4 & 2 & 3 & 2 & 17 & $\mathbf{7 . 2}$ \\
Total & 2 & 13 & 82 & 84 & 23 & 10 & 22 & 236 & $\mathbf{1 0 0 . 0}$ \\
(\%) & $\mathbf{0 . 8}$ & $\mathbf{5 . 5}$ & $\mathbf{3 4 . 7}$ & $\mathbf{3 5 . 6}$ & $\mathbf{9 . 7}$ & $\mathbf{4 . 2}$ & $\mathbf{9 . 3}$ & $\mathbf{1 0 0 . 0}$ & \\
\hline
\end{tabular}


Table 4 Verbal protocol frequency analysis for 30 American lenders

Legend: (refer to Table 1)

$\mathrm{A}=$ Description

$\mathrm{B}=$ Recall

$\mathrm{C}=$ Preconception

$\mathrm{D}=$ Inference

$\mathrm{E}=$ Question

$\mathrm{F}=$ Action

$\mathrm{G}=$ Comment

$\mathrm{H}=$ Total number

$\mathrm{I}=$ Total percentage
Legend: (refer to Table 2)

$\mathrm{CBT}=$ Calculus-Based Trust

$\mathrm{KBT}=$ Knowledge-Based Trust

$\mathrm{IBT}=$ Identification-Based Trust

$\mathrm{U}=$ Utility

$\mathrm{I}=$ Importance

$\mathrm{R}=$ Risk

$\mathrm{C}=$ Competence

$\mathrm{CJ}=$ Coordinator Judgment

$\mathrm{O}=$ Others

\begin{tabular}{||cccccccccc||}
\hline CBT & A & B & C & D & E & F & G & H & I \\
KBT & - & 1 & 23 & 19 & - & - & 3 & 46 & $\mathbf{2 5 . 3}$ \\
IBT & - & - & - & - & - & - & - & - & \\
& & & & & & & & & \\
U Low & - & - & 6 & 4 & - & - & - & 10 & $\mathbf{5 . 5}$ \\
U Med & 1 & - & 3 & - & - & - & - & 4 & $\mathbf{2 . 2}$ \\
U High & - & - & 1 & - & - & - & - & 1 & $\mathbf{0 . 5}$ \\
I Low & - & - & - & 2 & - & - & - & 2 & $\mathbf{1 . 1}$ \\
I Med & 1 & - & 1 & - & - & - & - & 2 & $\mathbf{1 . 1}$ \\
I High & - & - & - & - & - & - & 1 & 1 & $\mathbf{0 . 5}$ \\
R Low & - & - & 1 & - & - & - & 1 & 2 & $\mathbf{1 . 1}$ \\
R Med & - & - & 6 & 2 & 1 & - & - & 9 & $\mathbf{4 . 9}$ \\
R High & - & 1 & 7 & 4 & 2 & - & 1 & 15 & $\mathbf{8 . 2}$ \\
C Low & - & - & 10 & 19 & 16 & 1 & 2 & 48 & $\mathbf{2 6 . 4}$ \\
C Med & - & - & - & 9 & - & 1 & - & 10 & $\mathbf{5 . 5}$ \\
C High & - & - & - & - & - & - & - & - & \\
CJ Low & - & 2 & 6 & 1 & 5 & - & 2 & 16 & $\mathbf{8 . 8}$ \\
CJ Med & - & 1 & - & 1 & - & - & - & 2 & $\mathbf{1 . 1}$ \\
CJ High & - & - & 2 & - & - & - & 1 & 3 & $\mathbf{1 . 6}$ \\
& & & & & & & & & \\
Other & - & - & 4 & 3 & 1 & 1 & - & 9 & $\mathbf{4 . 9}$ \\
Total & 2 & 6 & 70 & 65 & 25 & 3 & 11 & 182 & $\mathbf{1 0 0 . 0}$ \\
\% $)$ & $\mathbf{1 . 1}$ & $\mathbf{3 . 3}$ & $\mathbf{3 8 . 5}$ & $\mathbf{3 5 . 7}$ & $\mathbf{1 3 . 7}$ & $\mathbf{1 . 6}$ & $\mathbf{6 . 0}$ & $\mathbf{1 0 0 . 0}$ & \\
\hline \hline
\end{tabular}


Table 5 Verbal protocol frequency analysis for $\mathbf{3 0}$ brokers

Legend: (refer to Table 1)

$\mathrm{A}=$ Description

$\mathrm{B}=$ Recall

$\mathrm{C}=$ Preconception

$\mathrm{D}=$ Inference

$\mathrm{E}=$ Question

$\mathrm{F}=$ Action

$\mathrm{G}=$ Comment

$\mathrm{H}=$ Total number

$\mathrm{I}=$ Total percentage
Legend: (refer to Table 2)

$\mathrm{CBT}=$ Calculus-Based Trust

$\mathrm{KBT}=$ Knowledge-Based Trust

$\mathrm{IBT}=$ Identification-Based Trust

$\mathrm{U}=$ Utility

$\mathrm{I}=$ Importance

$\mathrm{R}=$ Risk

$\mathrm{C}=$ Competence

$\mathrm{CJ}=$ Coordinator Judgment

$\mathrm{O}=$ Others

\begin{tabular}{||cccccccccc||}
\hline CBT & A & B & C & D & E & F & G & H & I \\
KBT & & 1 & - & 2 & & - & 1 & 44 & $\mathbf{2 6 . 8}$ \\
IBT & - & - & - & - & - & - & - & - & 1.8 \\
U Low & - & - & 2 & 7 & - & 1 & 2 & 12 & $\mathbf{7 . 3}$ \\
U Med & - & - & 1 & 1 & 1 & - & - & 3 & $\mathbf{1 . 8}$ \\
U High & - & - & 1 & - & - & - & - & 1 & $\mathbf{0 . 6}$ \\
& & & & & & & & & \\
I Low & - & - & - & - & - & - & 1 & 1 & $\mathbf{0 . 6}$ \\
I Med & - & - & - & - & - & - & - & 0 & $\mathbf{0 . 0}$ \\
I High & - & - & - & - & - & - & 1 & 1 & $\mathbf{0 . 6}$ \\
R Low & - & - & - & - & - & - & - & 0 & $\mathbf{0 . 0}$ \\
R Med & - & - & 7 & 2 & - & - & - & 9 & $\mathbf{5 . 5}$ \\
R High & 1 & 1 & 6 & 4 & - & - & 1 & 13 & $\mathbf{7 . 9}$ \\
C Low & - & 2 & 7 & 13 & 8 & - & 3 & 33 & $\mathbf{2 0 . 1}$ \\
C Med & - & - & - & 4 & - & - & - & 4 & $\mathbf{2 . 4}$ \\
C High & - & - & - & - & - & - & - & 0 & $\mathbf{0 . 0}$ \\
& & & & & & & & & \\
CJ Low & - & 1 & 9 & 3 & 9 & - & 3 & 25 & $\mathbf{1 5 . 2}$ \\
CJ Med & 1 & - & - & 1 & - & - & - & 2 & $\mathbf{1 . 2}$ \\
CJ High & - & - & 3 & - & - & - & 2 & 5 & $\mathbf{3 . 0}$ \\
& & & & & & & & & \\
Other & - & - & 5 & 1 & - & 1 & 1 & 8 & $\mathbf{4 . 9}$ \\
Total & 2 & 5 & 62 & 60 & 18 & 2 & 15 & 164 & $\mathbf{1 0 0 . 0}$ \\
\% $)$ & $\mathbf{1 . 2}$ & $\mathbf{3 . 0}$ & $\mathbf{3 7 . 8}$ & $\mathbf{3 6 . 6}$ & $\mathbf{1 1 . 0}$ & $\mathbf{1 . 2}$ & $\mathbf{9 . 1}$ & $\mathbf{1 0 0 . 0}$ & \\
\hline
\end{tabular}


Table 6 Consolidated verbal protocol frequency analysis for all categories

Legend: (refer to Table 1)

$\mathrm{A}=$ Description

$\mathrm{B}=$ Recall

$\mathrm{C}=$ Preconception

$\mathrm{D}=$ Inference

$\mathrm{E}=$ Question

$\mathrm{F}=$ Action

$\mathrm{G}=$ Comment

$\mathrm{H}=$ Total number

$\mathrm{I}=$ Total percentage
Legend: (refer to Table 2)

$\mathrm{CBT}=$ Calculus-Based Trust

$\mathrm{KBT}=$ Knowledge-Based Trust

IBT $=$ Identification-Based Trust

$\mathrm{U}=$ Utility

$\mathrm{I}=$ Importance

$\mathrm{R}=$ Risk

$\mathrm{C}=$ Competence

$\mathrm{CJ}=$ Coordinator Judgment

$\mathrm{O}=$ Others

\begin{tabular}{|lccccccccc||}
\hline CBT & A & B & C & D & E & F & G & H & I \\
KBT & - & 1 & 61 & 64 & - & - & 5 & 131 & $\mathbf{2 2 . 5}$ \\
IBT & - & 3 & 2 & 5 & & & - & 10 & $\mathbf{1 . 7}$ \\
& & - & - & - & - & - & - & - & \\
U Low & - & - & 11 & 16 & - & 2 & 3 & 32 & $\mathbf{5 . 5}$ \\
U Med & 1 & 3 & 7 & 3 & 1 & - & - & 15 & $\mathbf{2 . 6}$ \\
U High & - & - & 4 & 1 & - & - & - & 5 & $\mathbf{0 . 9}$ \\
& & & & & & & & & \\
I Low & - & 3 & - & 5 & - & - & 3 & 11 & $\mathbf{1 . 9}$ \\
I Med & 1 & - & 2 & - & 1 & - & - & 4 & $\mathbf{0 . 7}$ \\
I High & - & 1 & - & - & - & 1 & 4 & 6 & $\mathbf{1 . 0}$ \\
R Low & - & - & 2 & 3 & 1 & - & 1 & 7 & $\mathbf{1 . 2}$ \\
R Med & - & - & 24 & 5 & 2 & - & - & 31 & $\mathbf{5 . 3}$ \\
R High & 2 & 4 & 28 & 10 & 3 & - & 3 & 50 & $\mathbf{8 . 6}$ \\
C Low & - & 3 & 25 & 60 & 38 & 5 & 11 & 142 & $\mathbf{2 4 . 4}$ \\
C Med & - & - & - & 18 & - & 2 & - & 20 & $\mathbf{3 . 4}$ \\
C High & - & - & - & - & - & - & - & - & \\
CJ Low & 1 & 4 & 24 & 6 & 17 & - & 10 & 62 & $\mathbf{1 0 . 7}$ \\
CJ Med & 1 & 2 & 1 & 4 & - & - & - & 8 & $\mathbf{1 . 4}$ \\
CJ High & - & - & 8 & 1 & - & - & 5 & 14 & $\mathbf{2 . 4}$ \\
& & & & & & & & & \\
Other & - & - & 15 & 8 & 3 & 5 & 3 & 34 & $\mathbf{5 . 8}$ \\
Total & 6 & 24 & 214 & 209 & 66 & 15 & 48 & 582 & $\mathbf{1 0 0 . 0}$ \\
(\%) & $\mathbf{1 . 0}$ & $\mathbf{4 . 1}$ & $\mathbf{3 6 . 8}$ & $\mathbf{3 5 . 9}$ & $\mathbf{1 1 . 3}$ & $\mathbf{2 . 6}$ & $\mathbf{8 . 2}$ & $\mathbf{1 0 0 . 0}$ & \\
\hline & & & & & & & & & \\
\hline
\end{tabular}




\section{IMPLICATIONS FOR THE DEVELOPMENT OF ENTRE- PRENEURIAL INITIATIVES IN NIGERIA}

This study identified two types of influence that instant trust and instant cooperation can have on entrepreneurial development strategies and prospects in Nigeria. A first way in which instant trust and instant cooperation have an influence on entrepreneurial development in Nigeria is via the explicit conditionalities imposed by the larger society. One of the most important conditionality imposed by the Nigerian society is the cultural conditioning that is particularly potent in shaping entrepreneurial pursuits. Nigeria's cultural conditioning encourages unstructured proprietorial capitalism, otherwise known as 'underground economy'.

In Nigeria, as is the case in other developing countries, the underground economy is sizeable and solid. The structural composition of the Nigerian business climate allows for the recognition and acceptance of the towering influence of underground business activities. Informal lending practices are common wherever underground economies exist. The very essence of underground economies is the measures of informalities that provide avenues for eliminating legal constrains associated with organized settings and structures.

A second type of influence exerted by instant trust and instant cooperation on entrepreneurship is implicit conditionality. This concept refers to the ethnic and tribal divisions that exist in the Nigerian body polity. Discrimination along ethnic, tribal, religious, and even denominational lines are never laid out explicitly. Yet, they constitute the main factors that the informal lenders take into account in allocating their loan and investment funds. The never-ending religious, and ethnic riots have not supported entrepreneurial development as such actions can only invite negative tendencies within the ranks of informal lenders. For example, the Matasini riots of the early 1980s in Northern Nigeria, and the present spate of Sharia-induced riots in Kaduna, Zamfara, and other Northern States of the federation cement the application of the aforementioned unwritten rules of engagement by the informal lenders.

\section{CONCLUSION}

This research examined the trends in the role of instant trust and instant cooperation in lending decisions by informal lenders in Nigeria and the United States of America. The result indicates a sizeable influence of instant trust and instant cooperation on lending decisions during the initial stages of the lending process. There are slight disparities in the results between the evidence from Nigeria and that of the United States of America, particularly when the services 
of third parties or brokers are involved. In Nigeria for example, lenders employ trust as raw tools for analysing their risk-return continuum under conditions of 'limited information' thus making trust the sole deciding factor under conditions of 'limited rules and inadequate legal protection'. By direct analogy, this study observes that any structural setting that is founded on informalities can only enhance the application of the instant trust paradigm to determine the level of instant cooperation that informal lenders may be willing to give to would-be borrowers.

This limited opportunity for venture capital from informal lenders and business angels can only stifle entrepreneurial development to say the least, particularly in such economies where the formal finance sector is plagued with inconsistencies and frequent policy shifts. Where would-be entrepreneurs cannot raise capital from the formal finance sector for lack of collateral, and from the informal lenders where instant trust may be rightly construed to be a 'collateral', entrepreneurial initiatives may be subdued.

As the result indicates, the initial reaction of the informal lender to the lending opportunity is paramount. And until a borrower scales through this first hurdle, the dream of securing a loan for entrepreneurial initiative would only remain a dream. Admittedly, the two types of influence - explicit conditionality and implicit conditionality - will impact local economies in the same way. However, there are visible distinctions by region and State, based on traditional business practices and established norms founded on each region's cultural settings. In the final analysis, trust must be established for cooperation to take place. This article thus opines that the dearth of entrepreneurial development in Nigeria is fundamentally connected to the instant trust and instant cooperation paradigm.

The study tends to confirm the view expressed by Harrison et al. (1997) that in time compressed situations, Calculus-Based-Trust remains the most desirable tool. It also indicates that there are four key factors that may determine a categorical prediction of trusting cooperation, namely, perceived risk, importance of the trusting situation, utility of the situation for the trusting individual, and the trusting individual's perceived competence of the trusted individual.

By way of recommendation, this paper advocates the enhancement of policy dialogue between the Federal, State and Local governments, and informal/voluntary business groupings in Nigeria. This will provide the basis for supportive public policies at government level. The Federal government must also be willing to provide the financial resources and incentives to encourage both the informal lending channels, and the prospective entrepreneurs. 


\section{REFERENCES}

1 CARY, L. (1995) (ed.) The Venture Capital Report Guide to Venture Capital in the UK and Europe, (7th ed.) Henley on Thames: VCR.

2 EKPO, A.H. (1987) "Capital formation in selected West African countries: Theory and empirical evidence", Analisis Economico, 2.1: 3547.

3 FIET, J.O. (1991) "Network reliance by venture capital firms and business angels: An empirical and theoretical test", In N. Churchill et al. (eds.), Frontiers of Entrepreneurship Research: 445-55, Babson College, Wellesley, MA.

4 FREEAR, J., SOHL, J. \& WETZEL, W. (1996) "The informal venture capital market: Milestones passed and the road ahead", Paper presented at the fourth State of the art in Entrepreneurship research conference, Center for Entrepreneurial Leadership, Kansas City, MO.

5 FUKUYAMA, F. (1995) Trust: The Social Virtues and the Creation of Prosperity, London: Hamish Hamilton.

6 GAMBETTA, D. (1990) Trust: Making and Breaking Cooperative Relations, Oxford: Blackwell.

7 HALL, J. \& HOFER, C.W. (1993) "Venture capitalists' decisions in new venture evaluation", Journal of Business Venturing, 8: 25-42.

8 HARRISON, R., DIBBEN, M. \& MASON, C. (1997) "The role of trust in informal investment decision: An exploratory analysis", Entrepreneurship: Theory and Practice, 21, (4): 63-86.

9 LARSON, A. (1992) "Network dyads in entrepreneurial settings", Administrative Science Quarterly, 37: 76-104.

10 LEWICKI, R.J., \& BUNKER, B.B. (1995) "Developing and maintaining trust in work relationships", In R.M. Kramer, \& T.R. Tyler (eds.), Trust in Organizations: Frontiers of Theory and Research: 357-89, Thousand Oaks, CA: Sage Publications.

11 LOW, M. \& SRIVATSAN, V. (1993) "What does it mean to trust an entrepreneur?" Paper presented at Third Global Entrepreneurship Research Conference, Lyon, France.

12 Marsh, S. (1995) "Formalising trust as a computational concept", Technical Report, CSM 133, Department of Computer Science and Mathematics, Stirling University.

13 MASON, C.M. (1996) "Informal venture capital: Is policy running ahead of knowledge?", International Journal of Entrepreneurial Behaviour and Research, 2: 4-14.

14 MASON, C.M. \& HARRISON, RT. (1996a) "Informal venture capital: A study of the investment process, the post-investment experience and investment performance", Entrepreneurial and Regional Development, 8: $105-26$. 
15 MASON, C.M., \& ROGERS, A. (1996) "Understanding the business angel's investment decision", Working paper No. 11, Venture Finance Research Project, Dept. of Geography, University of Southampton.

16 MEYERSON, D., WEICK, K.E. \& KRAMER, R.M. (1996) "Swift trust and temporary groups", In R.M. Kramer, \& T.R. Tyler (eds.) Trust in organizations: Frontiers of theory and research: 357-89. Thousand Oaks, CA: Sage Publications.

17 UMOREN, N.J. (1998) "The first five critical pathways to entrepreneurial development", An unpublished paper presented at a workshop on entrepreneurial development. University of Uyo, Uyo.

18 TYEJBEE, T. \& BRUNO, A. (1994) "A model of venture capitalist investment activity", Management Science, 30: 1051-66. 